DOI: 10.12731/2227-930X-2016-3-87-105

\title{
STUDY OF THE EXPERIENCE OF USE OF INTERMODAL TECHNOLOGY IN THE ORGANIZATION OF PASSENGER TRANSPORTATIONS
}

Paramonova L.A.

This article examines the practice of applying intermodal technology and a single transportation document in the organization of passenger transportations, contains a review of the projects on the use of intermodal technology from theoretical point of view, an analysis of the implemented models.

Keywords: intermodal transportations of passengers; carriers' cooperation; a single transportation document; passengers' demand.

\section{Introduction}

Currently, the transport sector is developing rapidly, it's being reorganized, and it's undergoing significant changes. This is due to the increase in needs for constant movements with minimum time costs, as well as due to the changes in consumer preferences.

Much attention is paid to the development of the passenger transport system in the Moscow region. In particular, the lecturers of MADI investigate the issues of improving the organization of taxi transportations in the Moscow Agglomeration by solving the problems of territorial forecasting and planning [1], developing approaches to establishing the optimal number of taxi cars in megalopolis [2], [3]. There are also studies in the field of security of transportation by taxi-cars [4]; the problems and the prospects for the development of the transport system of the Moscow Agglomeration are studied, and 
new approaches and concepts for the modernization of the transport industry are proposed [5], [7].

Improving the work of certain types of transport is an important direction of development of the transport industry, but it isn't sufficient for meeting consumers' requirements (the main requirements are comfort, safety, minimum time expenses, the cost of transportation, and, if available, the possibility of purchasing tickets via Internet). To meet these requirements and to organize passenger transportations "from door to door" it is necessary to build an effective system of cooperation between different modes of transport in which transportation would be "seamless", i.e. providing maximum comfort for the passengers in the moment of docking. Docking shouldn't create difficulties for passengers and give inconveniences.

This task is fulfilled by the organization of intermodal / multimodal passenger transportations.

Intermodal passenger transportations should be regarded as the carriage of passengers, baggage and hand luggage from origin to destination by more than one mode of transport under a single transportation document, in which the responsibility for the entire transportation process, including docking in interchange nodes, is carried by a specific carrier / s or by a third-party operator [6].

Seeing the specifics of the technology of organization of this type of passenger carriages, as well as seeing the existence of different needs of passengers depending on the type of traffic (urban, suburban, intercity and international) it's more appropriate to use intermodal technology for organization of passenger transportations over long distances with the participation of such transport modes as aviation, rail, automobile and sea transport. This is due to the presence of a person responsible for docking in interchange nodes, which involves the release of a passenger from the necessity to solve the problem himself and from financial losses arising from the loss of docking, and the presence of obligation of a responsible person to 
resolve the failure situation and to deliver passengers to their point of destination.

This article investigates the experience of implementing of intermodal technology in foreign countries, as well as the Russian practice of using a single transportation document as one of the key components of intermodal / multimodal passenger transportations, and identifies the fundamental principles of this type of transportations.

\section{Overview of documents on the issues of construction of intermodal passenger transportations}

In Europe to the development of intermodality is paid much attention. Taking into account the specifics of European transport network (high level of development of rail network), the main mode of transport for long-distance transportations is railway, not bus.

The issues of implementation of intermodal technology of passenger transportations and of determination of its effectiveness, evaluated by economic component, technical and environmental aspects, are the subjects of investigation of many projects carried out by the European Commission's request.

These include the "Review of the current intermodality situation" [14].

This paper analyzes the current state of the development of intermodal transport in Europe on the basis of the composed scenarios for the evolution of the European transport network and on the determination of the ratio of social expenditures and incomes according to these scenarios. In this project there is conducted a study which aims to analyze what role will be referred to intermodal transport, or what value intermodality between air transport and other modes of transport will be in the airport of the future.

There are two types of intermodal transportations involving the airport:

1. transportation from the airport to the city center; 
2. integration of the airport to the regional or national networks of other modes of transport.

In the description of various types of cooperation between air and other modes of transport (bus and rail) and in the analysis of passenger demand for such intermodal transportations the importance of such differentiation is emphasized.

In addition to the examples of intermodal cooperation between different modes of transport, implemented in practice, in this project a theoretical description, calculations, analysis of results and recommendations for the organization of intermodal transportations are presented. In the study there were developed several models to estimate the demand for intermodal transportations, which are based on different criteria, expressed through a system of quantitative indicators with varying degrees of accuracy, there was conducted an analysis of the dependence of the region of service from the time it takes to get to the airport, and there were identified appropriate schemes of intermodal transportations. Calculations of the amount of investments to the implementation of the project and of the economic impact were also carried out by experts.

These design, technological and research solutions can serve as a basis for the organization of intermodal passenger carriages in Russia. Factors affecting the demand, transportation options will change due to the specifics of the Russian transport system, but the approaches and methods used in these studies may be the same.

The project "Intermodal passenger transport in Europe" [21] is also dedicated to the research of intermodal technology. It highlights the main principles that should be implemented in the organization of intermodal passenger transportations:

- a high degree of integration of the carriers operating different modes of transport;

- news alert of passengers throughout the transportation "from door to door"; 
- integrity;

- cooperation of different modes of transport, implying common rules and requirements;

- maximizing the use of the benefits of each transport mode involved in intermodal transportation;

- a unique information space;

- the cost benefit for the consumer compared to the total cost of carriage on individual segments.

In this paper the insufficiency of the number of studies (lack of statistical data, failure to prove the efficiency of these traffic to reducing the impact on the environment, the lack of effect assessment methods) is highlighted.

There are many documents on the development of intermodal passenger transportations in specific European countries. Models are built there using the methods used in research aimed at the development of intermodality in Europe in whole, also scenarios for the development of intermodal transport, taking into account features of a particular country describes are described. All the documents lead to the same conclusion - the need to use intermodal technology in passenger transportations. Tools and approaches to the study differ as well as the conclusions [16], [17], [18], [19].

\section{Models used in the projects}

According to the standard travel demand analysis conducted in "Review of the current intermodality situation" [14], the methodology of identifying passengers' demand on intermodal carriages is based on the linear price-duration model, where the utility of the traveller depends on the total travel time and the price of the tickets. In this approach only two factors are taken into account as the main elements of choice for a passenger, when deciding whether to travel and when choosing a travel mode: travel price and journey time (frequency is considered to be another dimension of time of travel). Travel time 
includes several parameters. Among them in the case of an air journey are: time spent on the travelling to the airport, time spent in the airport on completing departure formalities, time on the plane, time spent reaching the final destination, and also time lag between preferred time of arrival and actual time of arrival. This last element is directly linked to the frequency of services. This is the reason why frequency is linked to the journey time component of the travel.

This model is expressed through a function:

$$
\mathrm{U}(\mathrm{t}, \mathrm{c})=Q_{\mathrm{t}}{ }^{*} \mathrm{t}+Q_{\mathrm{c}}{ }^{*} \mathrm{c},
$$

where $\mathrm{t}$ is the total travel time, and $\mathrm{c}$ is the total travel cost.

The traveller will choose the mode with a larger utility.

It means that mode $i$ is chosen if $U_{i}>U_{j}$.

Usually faster modes are more expensive and therefore the choice will depend on how sensitive to time the passenger is. From this model they derive the "value of time", which can be defined as the value of one hour of travel time: it is the price the traveller would be willing to pay in order to decrease its travel time by one hour.

$$
V_{\mathrm{t}}=-\frac{Q_{\mathrm{t}}}{Q_{\mathrm{c}}}
$$

Another way of defining the demand is to compute the generalized cost of travel. The mode chosen is the mode with the smaller generalized cost. The generalised cost takes into account as well the ticket fare than the value of time for the passenger converted into monetary value:

where:

$$
C_{\mathrm{g}}=\mathrm{p}+\mathrm{v} * \mathrm{t},
$$

$\mathrm{C}_{\mathrm{g}}$ - is the generalized cost;

$\mathrm{v}$ - is the passenger value of time;

$\mathrm{t}$ - is the transport journey time.

There is also another parameter which should be evaluated - the indifference value between two transport modes (1 and 2). It is the value of time for which the passenger is indifferent between taking one of these modes, i.e. for which the generalized cost is the same. 


$$
\begin{gathered}
v_{0} \text { is such as } p_{1}+v_{0}^{*} t_{1}=p_{2}+v_{0}^{*} t_{2} . \\
v_{0}=\frac{p_{2}-p_{1}}{t_{1}-t_{2}} .
\end{gathered}
$$

Another methodology gives more accurate value [22].

The demand on transportations depends on passengers' sensitivity-fix parameters. Variable parameters influencing transport choice are grouped into 3 main categories: time, expenses and attractiveness and quality (as one parameter). The demand distribution model suggested by this source consists of these parameters each of which includes a number of characteristics. The demand equation is the next: $\mathrm{C}$ is a total cost, $\mathrm{T}$ is total time and $\mathrm{S}$ is attractiveness and quality.

$$
\begin{gathered}
\mathrm{D}=\mathrm{C}+\mathrm{T}+\mathrm{S} \\
\mathrm{C}=-\left[\mathrm{Q} * C_{\mathrm{ia}}+\varepsilon^{*} \mathrm{Q}_{\mathrm{ia}}\right],
\end{gathered}
$$

where $C_{\mathrm{ia}}-$ a sum of journey cost from departure "i" to destination "a";

$\mathrm{Q}$ - passengers' sensitivity to journey cost;

$\mathrm{Q}_{\mathrm{ia}}-$ cost to/from airport/station;

$\varepsilon$ - passengers' sensitivity to cost to/from airport or station.

$$
\mathrm{T}=-\left[\alpha^{*} T_{\mathrm{ia}}+\gamma^{*} A_{\mathrm{ia}}+\delta^{*} W_{\mathrm{ia}}\right]
$$

where $T_{\text {ia }}$ - the sum of journey time;

$\alpha$ - passengers' sensitivity to journey time;

$A_{\text {ia }}$ - time to/from airport/station;

$\gamma$ - passengers' sensitivity to time to/from airport or station;

$W_{\text {ia }}$ - walking/waiting time;

$\delta$ - walk/wait time sensitivity.

The first two factors, cost and time, have negative values, the smaller the value the better for the passenger.

$$
\mathrm{S}=\beta^{*} H_{\mathrm{ia}}+\lambda * P_{\mathrm{ia}}+\mu * S_{\mathrm{ia}}
$$

where $H_{\mathrm{ia}}$ - the sum of frequency; 
$\beta$ - passengers' sensitivity to frequency;

$P_{\text {ia }}$ - competitiveness;

$\lambda$ - passengers' sensitivity to competitiveness;

$S_{\text {ia }}$ - on-board services;

$\mu$-passengers' sensitivity to on-board services.

Attractiveness is the only attribute with a positive value, since the higher the quality the better from the passenger point of view.

\section{Methods and results of the suggested models}

The first model is based on the idea of identifying the demand on transportations through the indicators of utility, value of time and the indifference value between two transport modes. At first there should be collected data about passengers' sensitivity to the parameters.

So far, only time and price have been taken into consideration; in fact other dimensions can play a role in the choice made by the passenger. There are other complementary elements of choice, related to quality of travel mode, which should be taken into account, such as:

- Connection issues at interchange points;

- Comfort and on board services;

- Service integration between modes or between operators;

- Information services;

- Security, reliability and delays.

For example, the ratio of comfort can be identified by some integral value. To get this indicator there should be held passengers' surveys in which passengers give marks to different parameters which are valued by some conditional scale, each indicator should be assigned its measure of significance.

The second model takes into account much more variable parameters, which are grouped in 3 categories. Fix parameters were introduced above as passengers' sensitivity to travel attributes. To study the sensitivity of passengers to eight different travel factors (ticket price, 
price to/from airport/station, travel time, time to/from airport/station, walking/waiting time, frequency, competition, on-board services) a questionnaire should be undertaken. All the factors used in demand model vary on 10-point scale in order to allow the same importance to each factor.

Variable factors considered for the described demand distribution model are the following:

- Journey Cost (it consists of flight cost, journey cost by rail);

- Cost to/from airport/station;

- Time (flight time, time to/from airport/station, and walking/ waiting time);

- Competitiveness;

- Frequency;

- On-board services;

- Seat ratio.

The second model gives a more accurate value of the demand as it takes into account more factors. After comparing each factor separately the result shows a percentage of passengers choosing the examined transport mode. The form of equation is such that the model will always forecast passenger distribution between $0 \%$ and $100 \%$. This model was constructed for the cooperation between air and rail transport. But for other kinds of transportation there should be created a familiar model with other factors and parameters. The ways of identifying the value of each parameter will be different. But the approach will be the same. It can be suggested to create a different questionnaire asking passengers to rank their priorities instead of assigning an importance to each attribute. The place of survey is very important. Passengers given the choice to travel both modes will be the main source of information. Surveys can be conducted at travel agencies to get a better understanding of passengers' trade off between various travel factors. Passengers' feedback and awareness of their expectations will help to identify the reduction in demand. 


\section{Overview of the practice of the organization of intermodal passenger transportations}

\subsection{Foreign practice}

One of the prerequisites of intermodal transportation is the presence of a single transportation document. A number of companies use an integrated (single) ticket for intermodal passenger transportations over long distances.

As already noted, due to the specifics of the EU transport sector, consisting in a highly developed railway network, in most cases, the cooperation takes place with the participation of this type of transport.

The most interesting in terms of passenger service and baggage handling technologies are experimental Intercity train (Intercity Experimental (ICE) train) Lufthansa; AiRail service (cooperation of Lufthansa and Deutsche Bahn AG (DB) - railway operator in Germany); Air France - Thalys International trains.

In 1985, Lufthansa became the first airline that had applied rail correspondence instead of the air in the frameworks of AiRail service. Rail correspondence was organized between the airports of Frankfurt and Düsseldorf, between Frankfurt Airport and the main train station in Cologne. For these rail links the Intercity Experimental (ICE) trains were used.

The services of these express trains could only be used by Lufthansa passengers; they were offered the same services as on board an aircraft: a reservation system for seats; luggage check-in at the railway station; food and drinks on board. In 1993, Lufthansa stopped operating these trains due to high costs [20].

However, in 2001, Lufthansa, in cooperation with DB, as well as with American Airlines and Emirates airlines, entered into an agreement to create an AIRail service. As part of this cooperation, Lufthansa had the opportunity to reserve seats on DB trains, rather than the whole carriages, as when using Intercity experimental trains. 
To date, AIRail service is also offered on the links between the main station in Stuttgart and the Frankfurt International Airport and between the main station of Cologne and Frankfurt.

All passengers receive boarding passes for connecting flights from Frankfurt International Airport, at the check-in desks, located on the railway station.

The product of interaction between Lufthansa, DB and other airlines allows passengers to register their luggage at the railway station and use the high-speed train service. At that they do not need to carry their luggage from the train to the airport themselves. The development of this service required not only the cooperation of Lufthansa and DB, but also the interaction with Frankfurt International Airport in terms of safety, due to the introduction of new requirements by ICAO (International Civil Aviation Organization) for mandatory examination of baggage before being fed into the baggage system of the airport.

In case of flight cancellation, passengers have the right to return back by train and exchange the air ticket for a valid train ticket either at Lufthansa or DB counter.

In 1994, thanks to the cooperation of Air France and SNCF (national society of railways in France) within the framework of the TGV Air agreement, there was launched a railway communication between Lille and Charles de Gaulle airport. On this line high-speed trains TGV operated [15].

The agreement was based on the condition that Air France cancelled flights from Lille to Charles de Gaulle. Such a bimodal product didn't concern the luggage registration, but allowed passengers to purchase a single ticket for an international flight, preceding or following TGV journeys. The tariff for travelling by train is displayed in the Air France reservation system. To date, according to the display rules of the reservation system, which presuppose the priority of offers with minimal time costs, air transportation is first displayed separately, only then the TGV + airplane. 
The ticket contains at least 2 coupons: one for the TGV train (abbreviation Train à Grande Vitesse - high-speed train), the other for an international flight. However, the drawback of this ticket is that not all requisites needed for railway transportation are indicated in this ticket. In this regard, the passenger must in order to avoid delay arrive at the station in advance (more than 20 minutes) and exchange this coupon for the SNCF railway ticket. Unlike a passenger itinerary receipt, a railway ticket includes the number of the seat and the same of the carriage.

The second disadvantage is the possibility of checking-in passengers only at a limited number of railway stations without concerning the luggage. In this regard, passengers are forced to carry luggage to the airport building on their own. The time interval between the TGV train arrival and the flight departure depends on the terminal of departure and can reach up 1.5 hours.

Thus, this scheme does not fulfill the principle of minimizing time costs and does not provide a high level of quality of transport services.

In 2001, Air France cancelled flights between the airport Charles de Gaulle and Brussels. All passengers of Air France were transported from Brussels to Charles de Gaulle by an international operator of high-speed trains Thalys International trains, which, for its part, was obliged to reserve at least one carriage for Air France passengers and to increase train frequencies. This agreement differs from TGV AIR in that passengers are checked-in at the main train station in Brussels, their baggage is checked in, weighed, labeled and transported to the airport in a separate luggage compartment, but the passengers need to carry their luggage to the airport building themselves. To date, the range of airlines participating in the agreement has significantly expanded, the number of railway routes has also increased. The SkyTeam Alliance has signed a code-sharing agreement with Thalys International trains on the transportation of passengers by rail from Amsterdam Schiphol Airport to the central railway station in Belgium 
Antwerp-Centraal and the southern railway station in Brussels Bruxelles Midi / Brussel Zuid.

\subsection{Analysis of russian practice}

This type of transportation is actively used in foreign countries, there are only a few examples in the Russian Federation. Until recently, only Russian airlines were participants in such transportations. Recently, a correspondence with an air segment was organized to the airport "Simferopol" and a bus correspondence from the international airport "Simferopol" to the cities of the Crimea [8].

In the Russian Federation there are 4 vivid examples of the use of a single transportation document for transportation by various modes of transport with the participation of Russian transport companies:

- single ticket "Aeroexpress + metro";

- single ticket "Aeroflot + DB";

- "Troika","Strelka" and the combined card "Troika" and "Strelka";

- a single ticket "Fly \& Bus" of Pobeda airline and bus carriers.

Aeroexpress LLC offers 3 variants of single tickets, including a trip / several trips by Aeroexpress and a trip /trips by metro, MCC (Moscow Central Circle) or bus / trolley or tram: "Plus Metro", "Between airports", and "Business trip". These tickets differ in the number of included trips by Aeroexpress and by metro, MCC, bus / trolley / tram [9].

Disadvantages of all types of tariffs are the cost characteristics and the lack of the possibility of purchasing through the Internet. Tickets for these tariffs are sold only through ticket offices, ticket machines and turnstiles.

From an economic point of view, this ticket is unprofitable, since its cost corresponds to the total cost of tickets purchased through a terminal or a cash desk, it is more convenient and quicker to purchase an electronic ticket for Aeroexpress and a ticket for the metro in the ticket 
machine separately. Thus, the principle of intermodal transportation, which consists in reducing financial costs, is not fulfilled.

The technology of a single transportation document has also been implemented by Aeroflot in cooperation with the Deutsche Bahn in the "Rail \& Fly" programme [10].

The advantages of this programme include:

- large route network (more than 600 destinations);

- the possibility of booking a seat on the train on the airline's website;

- a single ticket;

- the possibility of selecting the mode of transport for a trip to the destination at the booking stage;

- a single reservation number, which implies connecting the DB to the Saber reservation system.

The disadvantages include the need for a passenger to print a railway ticket, similar to a boarding pass, in the terminal after arrival. To solve this problem, DB company can introduce electronic tickets like electronic boarding passes. However, this will require large financial investments.

Currently, ticket agglomeration system is represented by cards "Troika", "Strelka" and the combined card "Troika" and "Strelka" [11], [12]. Troika" enables passengers to pay for travelling by metro, by the MCC, by Moscow ground passenger transport, by suburban trains, in Aeroexpress, etc. "Strelka" is valid in Moscow Region and the combined card - in Moscow and in Moscow Region.

These cards are also examples of the use of a single transportation document. The inability to implement via the Internet, which is substantiated by the technology used for reading, can be attributed to the disadvantages of these transportation documents. These maps are used in urban and suburban communications and are not personal.

The service "Fly \& Bus" assumes the use of a single ticket "airplane + bus", which allows passengers to get from the airports to the nearest major cities on a special transfer [13]. 
Purchasing of the Fly \& Bus service guarantees the transportation of the passenger to the destination even in case of late arrival of the transfer to the airport.

The main idea of interaction between bus carriers and Pobeda airline is to reduce the cost of transportation and ensure comfortable transportation to the final destination for passengers. It also has a result in the form of development of the route network of the airline and the attraction of additional passenger traffic for bus companies. Reduced tariff is achieved by choosing the least loaded airports with lower airport charges and then organizing a special transfer for passengers to major cities. The bus service is organized from Bratislava airport to Vienna and back, and also in the directions: Bergamo - Milan - Bergamo, Allgau - Memmingen - Munich / Zurich - Allgau-Memmingen, Gyumri - Yerevan - Gyumri, Pisa - Florence - Pisa.

Despite the fact that this ticket is unified, it consists of two separate documents: the passenger itinerary receipt for the flight and a document confirming that the bus transfer to the final destination will be provided to the passenger at the airport of arrival. This is due to the peculiarities of the ticket sales system of air transport and the Air Transport Settlement System (ATSS). The form of the itinerary receipt is unified and uniformed for all airlines. Therefore, it is not possible to make changes and add additional information to the form to date. In addition, this would require the connection of bus carriers to ATSS, which would require significant financial investments. At the moment, this is inappropriate and inefficient. In connection with the foregoing, the most logical and at the same time the only variant of providing a single ticket is to compose two separate documents and send them in one letter to the passenger's e-mail.

A bus correspondence from the international airport "Simferopol" to the popular cities in the Crimea back has been arranged in Russia within the framework of the Fly \& Bus project with the participation of PJSC Aeroflot-Russian Airlines. Autoexpress "Fly \& Bus" departs from the 
airport terminal area, the time of departure / arrival of buses is docked with the flight arrival / departure schedule (including at night). The disadvantage of this service is that at the moment passengers have to buy separately a ticket for the plane to the airport of Simferopol and a ticket for the autoexpress. It is possible to buy tickets online, but in this case the passenger has to enter his data and pay twice. In case of flight delay, the passenger has to inform the bus carrier himself, the Fly \& Bus controller will offer the passenger a trip on the nearest flight of the Autoexpress. The absence of the option of automatic informing of the bus carrier about the flight delay indicates that the interaction scheme is inadequate.

Thus, this transport cannot be classified as intermodal, since the principle of a single ticket is not implemented.

\section{Conclusion}

At present, one of the main tasks of the development of the transport industry is the creation of a system of interaction of various modes of transport to meet the requirements of passengers and carry out the transportation of passengers "from door to door."

The organization of intermodal passenger transportation represents an innovative and promising direction for the development of the transport industry. This technology allows you to combine the advantages of each mode of transport and make transportation more efficient.

The examination of models, described above, shows that to make an adequate model it is necessary to work out a good questionnaire which would include all the parameters that influence on passengers' demand, to choose the appropriate place of survey. Value scale is also important. There can be offered different kinds of valuing, e.g. asking passengers to assign an importance to each attribute, the $2^{\text {nd }}$ variant is to ask them to rank their priorities. The other variant is to combine both approaches.

The study of the experience of the organization of intermodal passenger transportations and of the practice of use of a single transportation 
document leads to the conclusion that due to the varying degree of development of ticket-sale and reservation systems of different modes of transport, as well as due to the peculiarities of functioning of the aviation industry, a single transportation document for the organization of intermodal transport involving air transport must include at least two forms: one for an air segment, the second for another mode of transport. The principle of a single ticket in this case will be realized due to the fact that a passenger gets the transportation document in one letter by e-mail, the passenger data is entered once, the payment is made by one payment.

The introduction of intermodal technology will meet the requirements of passengers, increase the attractiveness and efficiency of the transport industry.

\section{References}

1. Bludyan N.O., Moroz D.G., Kheifits P.I. Territorial planning of taxomotor transport in urban agglomeration // Automation and control in technical systems. 2014. No. 1.1; URL: auts.esrae.ru/8-160 (date of circulation: March 24, 2017).

2. Bludyan, N.O. Problems of the organization of taxi transportations in the Moscow metropolis / N.O. Bludyan // Motor company. 2012. No. 10, pp. 11-14. - URL: http://www.atp.transnavi.ru/?number $=1210$ (reference date: March 15, 2017).

3. Bludyan N.O., Moroz D.G. "On the problem of justifying and establishing the optimal number of taxi cars in megacity" / N.O. Bludyan, D.G. Moroz //Motor company. 2013. No. 10, pp. 5-8.

4. Bludyan N.O. "Evaluation of the influence of quality of legal regulation on safety of taxi transportations" / N.O. Bludyan // Bulletin of the Moscow Automobile and Road Construction State Technical University (MADI). 2016. № 4 (47).

5. Bludyan N.O. "An alternative approach to the concept of modernization of the transport system of the Moscow metropolis" / N.O. Bludyan // Motor Company. 2013. No. 7, pp. 2-6. 
6. Bludyan N.O., Paramonova L.A. "Concerning the problem of formalisation of the terms "intermodal" and "multimodal" passenger carriages"/ Automobile. Road. Infrastructure. 2017 (1 (11)).

7. Pistun E.I., Bludyan N.O., Moroz D.G., Kheifits P.I. “Aglomeration problems of organization of an effective transport system" // Automation and control in technical systems. 2014. No. 2; URL: auts.esrae. ru/10-161 (date of circulation: March 24, 2017).

8. Autoexpress Fly \& Bus to the cities of Crimea from the airport of Simferopol. - URL: http://www.aeroflot.ru/us-ru/special_offers/business_travel/autoexpress_crimea (date of circulation: 15.03.2017).

9. Tariffs for Aeroexpress. - URL: https://www.aeroexpress.ru/en/forPassengers/prices.html (date of circulation: 15.03.2017).

10. Interaction between Aeroflot and DB. - URL: http://www.aeroflot.ru/ cms/special_offers/bahn_ag (date of circulation: 15.03.2017).

11. "Troika" and "Arrow" are now available in one card. - URL: http:// troika.mos.ru/passazhiram/news/trojka/trojka_i_strelka_teper_dostupny_v_odnoj_karte/ (reference date: 15.03.2017).

12. What is a single transport card of the Moscow Region "Strelka"? - URL: http://strelkacard.ru/faq/ (reference date: March 15, 2017).

13. Fly \& Bus service. - URL: https://www.pobeda.aero/information/information/flybus\#all (reference date: 15.03.2017).

14. "Review of the current intermodality situation" / Final version, European Organization for the Safety of Air Navigation, 2004.

15. "Intermodal Passenger Transport in Europe" funded by the European Commission's Directorate-General for Mobility and Transport DG MOVE.

16. Rail \& Fly in cooperation with Lufthansa Express. - URL: https:// www.lufthansa.com/uk/en/Lufthansa-Express-Rail-Fly (reference date: 15.03.2017).

17. "Recommendations of the link project: European forum on intermodal passenger travel" Paul Riley, Jacobs Consultancy, Alexandra Kumpoštová, Jacobs Consultancy / Association for European Transport and Contributors 2010. 
18. "Road Transport: A change of gear" Luxembourg: Publications Office of the European Union, 2012.

19. TGV AIR DESTINATIONS. - URL: http://www.airfrance.ru/RU/en/ common/resainfovol/avion_train/reservation_avion_train_tgvair_airfrance.htm (date of circulation: March 15, 2017).

20.AIRail Service. - URL: https://en.wikipedia.org/wiki/AIRail_Service (date of circulation: 15.03.2017).

21. "Integrated ticketing on long-distance passenger transport services"; directorate general for internal policies / policy department; b: structural and cohesion policies / transport and tourism; requested by the European Parliament's Committee on Transport and Tourism. Authors: TRT Trasporti e Territorio - Silvia Maffii, Alessio Sitran, Marco Brambilla, Angelo Martino MKmetric - Dr. Benedikt Mandel, Oliver Schnell, 2012.

22. Antonia Cokasova, "Air-Rail Inter-modality From Passenger Perspective".

\section{DATA ABOUT THE AUTHOR}

Paramonova Liudmila Andreevna, Student of Magistracy of Engineering Sciences

State Technical University - MADI

64, Leningradsky prospekt, Moscow, 125319, Russian Federation

paramonova_10A@mail.ru 